\title{
A
}

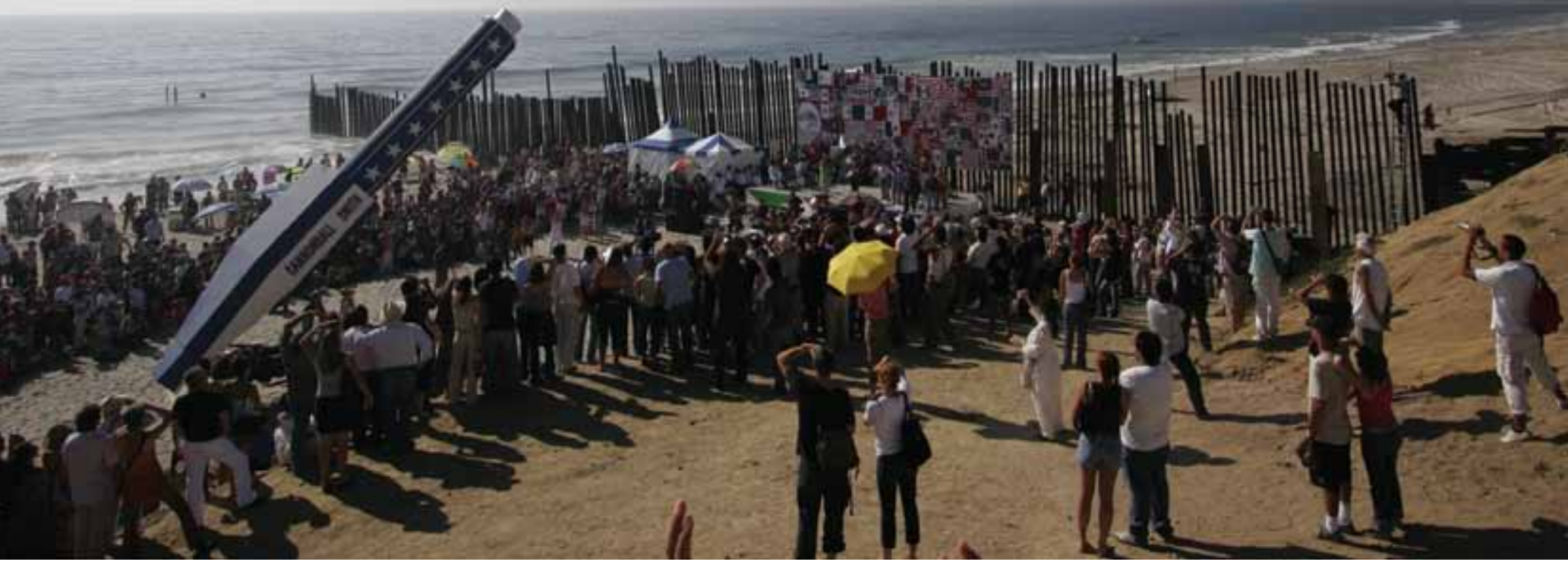

Javier Téllez

One Flew Over the Void / Bala perdida, 2005.

Tijuana, México

(Fonte: http://remezcla.com/) 


\section{Arte, América Latina e as fronteiras do mundo}

Luiz Sérgio de Oliveira*

RESUMO: A arte brasileira tem seus olhares tradicionalmente direcionados a horizontes distantes que têm o norte do mundo como foco, herança do período colonial, independentemente se esse interesse nos distancia de nossa realidade social, política ou cultural, daquilo que efetivamente nos distingue. Este ensaio propõe uma reflexão em torno das articulações entre arte, localidade e identidade no mundo contemporâneo.

PALAVRAS-CHAVE: arte, localidade, identidade, mundo contemporâneo

ABSTRACT: The Brazilian art have their eyes traditionally directed to distant horizons that have the northern world as focus, inheritance of the colonial period, regardless of whether this interest distances us from our social, political or cultural reality, from what actually distinguishes us. This essay proposes a reflection on the links between art, place and identity in the contemporary world.

KEYWORDS: art, place, identity, contemporary world

* Luiz Sérgio de Oliveira é artista e professor associado do Departamento de Arte e do Programa de Pós-Graduação em Estudos Contemporâneos das Artes da Universidade Federal Fluminense. 
Um dos grandes desafios dos artistas da América Latina, assim nos parece, é encontrar seu lugar no mundo. Na realidade, essa é uma questão que aflige qualquer artista em qualquer latitude; no entanto, para os latino-americanos, alinhados com o imaginário da arte ocidental, mesmo não sendo originários de um de seus centros propulsores, a questão se transforma em um desafio notável: como manter vinculações com os contextos sociais e culturais que dão lastro à sua produção de arte e, ao mesmo tempo, produzir uma arte que seja relevante para além de seus círculos mais imediatos.

Para muitos desses artistas, estar na América Latina, ser um artista latino-americano não é o bastante; é preciso ir além, é preciso atravessar fronteiras, ser internacional. Para tanto, é preciso estar sintonizado com as atualidades do mundo da arte, acompanhar as tendências que se revelam alhures, tanto na Europa (tradicionalmente entre a França e a Itália) quanto na cidade de Nova York a partir dos anos 1950. No entanto, a construção do sujeito, artista ou não, tem na nacionalidade um forte componente constituinte que o distingue e o singulariza; neste sentido, a transnacionalização, o tornar-se um outro nacional, o assumir outra nacionalidade para além dos registros burocráticos de cidadanias forjadas traz, como consequência, fraturas no sujeito, revelando uma impossibilidade consistente com os princípios da geografia cultural e com a natureza da vida. No entanto, muitos artistas, ancorados em dogmas que propugnam a universalidade da arte e induzidos por doutrinas que preconizam a urgência da atualidade, se esmeram em estar afinados com o universo internacionalizado da arte. Não são poucas as carreiras que se consolidaram na América Latina, e temos o Brasil como ponto de observação, por artistas que se distinguiram como replicadores do lado de cá do Atlântico de novidades no campo de arte surgidas em outras terras. Muitos desses artistas acabaram por incorporar modos de ser e de estar no mundo, para além de questões mais específicas da arte. Em muitos casos, diante da persistência entre nós de um alto grau de introjeção de uma subserviência cultural a dominar corações e mentes, herança do colonialismo, essas práticas são fomentadas e revelam sua utilidade como instrumento de distinção entre os próprios nacionais.

Por outro lado, é importante reconhecer que em um mundo que a cada rotação revela-se menor, que parece encolher, em um mundo no qual os meios de comunicação e de circulação da 
informação nos colocam em contato (superficial, é verdade) com diferentes culturas e outras realidades, é impensável a possibilidade de países, estados, regiões, cidades ou homens (e mulheres) permanecerem enclausurados em seu presente histórico, cerrados em suas culturas, preservados nas irrealidades de uma tradição que se pretende pura: os processos de contaminação e de transformação continuada não podem ser contidos nem tampouco estancados.

\section{2}

$\mathrm{Na}$ arte brasileira, os olhares apontam tradicionalmente para horizontes distantes que atravessam a linha do equador, pouco importando se essas atitudes e esse interesse revelem descompromisso com nossas vinculações sociais, políticas ou culturais, com aquilo que nos distingue. Afinal, diriam muitos, a arte é patrimônio do homem, desconhece fronteiras e nacionalidades e está além da pequenez de contextos e de identidades localizadas, devendo, ao contrário, reafirmar a condição universal da arte.

Aos povos periféricos do mundo contemporâneo vendem-se a ilusão de que as barreiras e os enfrentamentos nacionais deixaram de existir, como se vivêssemos em um mundo efetivamente planetário. Países como o Brasil, Argentina, Chile e México têm empreendido esforços extraordinários para se integrarem ao processo da globalização econômica, reconhecendo o princípio e a lógica que eliminam a possibilidade de um outro mundo para além do mundo globalizado, apesar de suas perversidades e de suas imperfeições. O processo de globalização do capitalismo, iniciado há séculos, atingiu sua maturidade e "uma escala propriamente global", na qual "declinam os Estados-nações, tanto os dependentes como os dominantes, [...] em benefício de centros decisórios dispersos em empresas e conglomerados movendo-se por países e continentes, ao acaso dos negócios". (IANNI, 2003, p. 38)

3

Não se pode desconhecer que há muito desapareceu da agenda política crítica no campo das artes visuais no Brasil qualquer articulação ou debate em torno do que seria uma arte brasileira, debate abandonado ao relento nos registros da história junto com seu interesse em pensar 
o Brasil e sua arte em torno de metáforas do "pau-brasil" na busca de um sentido para a antropofagia no campo da arte e da cultura. Há muito, a arte deixou de ser qualificada em termos nacionais, engolfada por debates pós-modernos que sugerem a obsolescência da questão em favor de uma globalização avassaladora, irrefreável e incombatível, e que obriga todos os povos e todas as nacionalidades a que se alinhem, que acatem e que se rendam ao modelo.

A noção de uma produção de arte que encontre seus sentidos e suas significações em contextos específicos - singulares e intransferíveis - parece sepultada em favor da vitória definitiva e irreparável da noção da universalidade da arte. Essa ideia de universalidade é fator imprescindível para garantir os trânsitos da produção de arte contemporânea por diferentes cenários sociopolíticos, desconhecendo as nacionalidades e os vínculos culturais dos artistas-produtores. Esses artistas, por sua vez, se comprazem em produzir acriticamente para um mercado que tem nas bienais internacionais, e mais recentemente nas feiras de arte, sua vitrine e seu foco.

Mesmo a produção de arte contemporânea que se articula em torno das localidades e das identidades em busca de respostas sensíveis a contextos sociais e comunitários específicos parece ambicionar sua internacionalização ou ao menos se deixa instrumentalizar pelo grande aparato espetacular das bienais internacionais que, mais do que nunca, escancararam sua condição coadjuvante ao mercado de arte. Nesses cenários, as singularidades são repetidas à exaustão de maneira rasa e descontextualizada, o que, ao fim e ao cabo, contribui de maneira definitiva para a homogeneização pelo cansaço e pelo excesso, como que a afirmar que, no fundo, tudo é igual a tudo e que o singular é uma quimera, reafirmando mais uma vez a força avassaladora da globalização que tem nas grandes mostras bienais internacionais um instrumento eficaz de formatação de ideias e de sensibilidades.

Tradicionalmente, o artista brasileiro teve a Europa como espelho no qual se mirava na busca de uma imagem que seguramente não seria a sua. A força de sedução da Europa fez com que durante décadas, que atravessaram séculos e vidas, a grande ambição do artista brasileiro fosse o prêmio de viagem ao exterior, inicialmente nos salões da academia de belas artes, em seguida - depois de muita peleja - nas seções de arte moderna e nos salões de arte moderna: 
todos com o epíteto de nacional. Isso implica em dizer que o principal prêmio dos salões nacionais tinha o porto como destino; isso significa que os grandes prêmios dos salões nacionais apontavam a partida e o adeus como recompensa para seus artistas mais talentosos. Esses prêmios levaram um grande contingente de artistas para o estrangeiro, na condição de pensionistas do Estado, em viagens por períodos que poderiam chegar a nove anos, conforme os casos de Rodolpho Amoedo e Rodolpho Bernardelli nos anos 1870 e Manoel Lopes Rodrigues nos anos 1880'.

Para esses artistas, a Europa era uma miragem, uma ficção da qual, ao final da permanência, retornariam à terra brasilis requalificados, modificados por um processo de imersão na história e na tradição do velho mundo capaz de transformá-los em disseminadores da arte e da cultura europeias, fortalecendo ainda mais os laços de transferência dos modos de ser e de viver da Europa para o lado de cá do Atlântico.

Em outros campos da produção artística - no caso, a música popular, território distante das preocupações universalizantes das artes visuais - e em outros tempos, devemos admitir, esses processos de contaminação cultural foram capazes de despertar reações e de deflagrar ressentimentos, conforme expresso por Carmen Miranda, a "pequena notável" portuguesa, ela mesma transmutada pela cultura brasileira e em seguida internacionalizada: "Me disseram que eu voltei americanizada, Com o burro do dinheiro, que estou muito rica, Que não suporto mais o breque do pandeiro, E fico arrepiada ouvindo uma cuíca" ${ }^{2}$. Mas não há dúvida de que vivemos em outro mundo.

\section{5}

Em um passado mais distante, a Europa já havia se apropriado das riquezas de suas colônias em processos de exploração que impuseram sacrifícios e abusos aos povos do mundo colonial na extração de seus recursos naturais e na privação de seus modos de ver, de pensar e de sonhar o mundo. De acordo com Eduardo Galeano,

entre 1503 e 1660, chegaram ao porto de San Lúcar de Barrameda [Espanha] 185 mil quilos de ouro e 16 milhões de quilos de prata. A prata transportada para a Espanha em pouco mais de um século e meio excedia em três vezes o total das reservas européias. E é preciso levar em conta que estas cifras oficiais são sempre minimizadas. (GALEANO, 2002, p. 34-35) 
Naquele cenário, as cidades de Potosí na Bolívia e Ouro Preto no Brasil conheceram sua fortuna nos anos de extração da prata e do ouro e subsistem na atualidade da exploração das reverberações de uma história que deixou suas marcas em monumentos e em obras de arte, lembranças de um tempo em que nutriam o desenvolvimento e a riqueza dos países ricos, de maneira que "desenvolviam-se os países desenvolvidos de nossos dias; subdesenvolviam-se os subdesenvolvidos". (GALEANO, 2002, p. 95)

\section{6}

Nos tempos atuais, o todo poderoso e tão decantado processo de globalização contempla apenas o capital e as mercadorias, entre as quais podem ser alinhados a produção e os serviços dos artistas. As lógicas que preconizam o fluxo planetário do capital e dos bens de consumo não se aplicam para o trânsito de gentes. Ao contrário. No cenário contemporâneo, predominam as restrições reguladoras das fronteiras, cada vez mais ativas na seleção do trânsito entre os diferentes eixos planetários - norte / sul, leste / oeste -, revelando as imperfeições de uma suposta sociedade global que tem deixado à margem, como nota Octavio lanni, extensas camadas da população planetária, representadas pelos habitantes da África e da América Latina, "duas imensas regiões do globo, compreendendo mais de 60 países, com cerca de $20 \%$ da população mundial e uma respeitável parcela dos seus recursos naturais". (IANNI, 2003, p. 23)

No entanto, todas as restrições não têm inibido o desejo, o sonho e o deslocamento de enormes contingentes de homens e de mulheres na busca de dias melhores, de melhores condições de vida e de trabalho, de acordo com uma tradição que remonta ao homem ancestral vagando pela face da Terra em busca de alimentos. Esse fluxo de gentes tem promovido, desde sempre, diálogos e contaminações entre diferentes culturas, um processo multifacetado que acarreta transformações culturais, ameaças, ressentimentos, conquistas e derrotas, aberturas e metamorfoses:

Ao mesmo tempo em que há muita perda, há muito ganho. É como se os indivíduos e as coletividades, etnias e minorias, grupos e classes, se humanizassem também por intermédio do vasto intrincado processo de globalização [...] tecendo o difícil e intrincado diálogo de modos de ser e imaginar; tecendo novos contrapontos de múltiplos singulares, de tal maneira que todos e cada um alcançam outras universalidades. (IANNI, 2003, p. 159) 
Para alguns teóricos que têm investigado as complexidades do processo de trânsito de gentes no mundo contemporâneo, o fechamento das fronteiras parece tentar impedir o contra-ataque das periferias do mundo, como que a reconhecer que "a vida cultural, sobretudo no Ocidente e também em outras partes, tem sido transformada em nossa época pelas vozes das margens". (HALL, 2003, p. 338) Na contemporaneidade, migrantes de países periféricos têm levado suas diferentes percepções de mundo para os centros, desafiando a suposta integridade cultural desses centros.

Os movimentos migratórios contemporâneos, tanto nos Estados Unidos, Europa e Ásia, parecem inverter o processo colonial como um cavalo de tróia da pós-modernidade: penetram nesses centros para, de dentro, intervir e transformar essas realidades. Como se estivéssemos assistindo a uma contaminação cultural invertida, não mais através da ação expansiva do centro, impondo imperialmente suas vontades, sua cultura, solapando outras possibilidades de ver e de sonhar o mundo, de articular passado, presente e futuro; como se, em uma ação não orquestrada que se articula na calada da história, agisse para corroer convicções arraigadas, certezas consolidadas, disseminando a desconfiança e as incertezas, propiciando o contágio, sugerindo o intercâmbio e a negociação. A respeito, o escritor e crítico literário Silviano Santiago afirma:

a maior contribuição da América Latina para a cultura ocidental vem da destruição sistemática dos conceitos de unidade e de pureza: estes dois perdem o contorno exato do seu significado, perdem seu peso esmagador, seu sinal de superioridade cultural, à medida que o trabalho de contaminação dos latino-americanos se afirma, se mostra mais e mais eficaz. (SANTIAGO apud IANNI, 2003, p. 87)

Nesse êxodo em direção aos centros, muitas vezes pouco se leva além de maneiras particulares de ver e de sonhar o mundo, singularidades que se apresentam a favor da contaminação e da transformação dos centros, prontas para um processo de refluxo contra a pretensa homogeneização cultural colonial, conforme apontado por Claude Lévi-Strauss:

Comecei a refletir em dado momento que nossa cultura agredia as outras culturas, das quais, por isso, me tornei testemunho e defensor. Agora, tenho a impressão de que o movimento 
inverteu-se, de que a nossa cultura está na defensiva frente às ameaças externas e, em especial, à ameaça islâmica. De golpe me sinto etnológica e firmemente defensor de minha cultura. (LÉVI-STRAUSS apud IANNI, 2003, p. 158)

Mas onde se situam os centros no mundo pós-moderno? E as periferias? Não se pode desconhecer que os processos de deslocamentos na pós-modernidade complexificam a oposição binária centro/periferia, assim como qualquer outra simplificação da mesma ordem. O mundo contemporâneo parece se caracterizar por um processo permanente de descentramento, com a criação de múltiplos de centros, sempre fluidos e em deslocamentos permanentes.

A vinculação entre antigos centros e periferias se apresenta de forma distinta na contemporaneidade, pondo em debate as assunções de um fluxo hierarquizante do passado colonial que já não encontra respaldo nas contaminações culturais contemporâneas, sendo suplantada por um processo de permanente intercâmbio no qual as periferias injetam suas contribuições culturais na transformação dos modos de ser, de viver, de pensar e de sonhar dos antigos centros, resultando em culturas em contínuo estado de acomodação. Conforme apontado pela artista norte-americana Adrian Piper,

a Europa agora está sofrendo o mesmo assalto externo em relação às suas entrincheiradas mitologias, convenções e organizações sociais que a vertente branca dos Estados Unidos sofreu a partir do movimento de direitos civis, a contracultura, o feminismo e os protestos anti-Guerra do Vietnam nos anos 1960. [...] A Europa precisará de um período sustentável de processamento cultural desses eventos por comunidades artísticas de forma a aprender como melhor representar estas mudanças para si mesma. (PIPER, 2008, p. 175)

Há muito, setores cultos das sociedades dos países mais desenvolvidos vêm saboreando a absorção de "certo tipo de diferença: um toque de etnicidade, um 'sabor' do exótico." (HALL, 2003, p. 337)

Se o pós-moderno global representa uma abertura ambígua para a diferença e para as margens e faz com que um certo tipo de descentramento da narrativa ocidental se torne provável, ele é acompanhado por uma reação que vem do âmago das políticas culturais: a resistência agressiva à diferença; a tentativa de restaurar o cânone da civilização ocidental; o ataque direto e 
indireto ao multiculturalismo; o retorno às grandes narrativas da história, da língua e da literatura; [...] a defesa do absolutismo étnico, de um racismo cultural que marcou as eras Thatcher e Reagan; e as novas xenofobias que estão prestes a subjugar a Europa. (HALL, 2003, p. 340)

9

Ao mesmo tempo em que o embaralhamento e a unificação dos sistemas de arte, acompanhando os preceitos de um mundo globalizado, abrem os mercados internacionais para o consumo da produção de alguns artistas latino-americanos, revelam outra forma mais avançada e mais sofisticada de dominação e de neutralização, na qual essa produção será absorvida e acolhida na exata medida em que se alinhar aos ditames desse sistema de arte internacional, abandonando-se qualquer dose excessiva de exotismo e de singularização, reafirmando processos que norteiam a correlação de forças no sistema de arte há muito tempo. Ainda no início do século passado, Tarsila do Amaral, em confidências familiares que acabaram por se tornar públicas, afirmava seus desejos e ambições, ao mesmo tempo em que revelava sua ingenuidade acerca da produção de arte de Paris:

Sinto-me cada vez mais brasileira: quero ser a pintora de minha terra. [...] Quero na arte, ser a caipirinha de São Bernardo, brincando com bonecas de mato como no último quadro que estou pintando. [...] Não pensem que esta tendência brasileira na arte é malvista aqui. Pelo contrário, o que se quer aqui é que cada um traga sua contribuição de seu próprio país. Assim se explica o sucesso dos bailarinos russos, das gravuras japonesas e da música negra. Paris está farta de arte parisiense. (ZÍLIO, 1982, p. 48)

A respeito, naquilo que denomina de "caráter apropriativo da arte euroétnica", Adrian Piper elabora sobre o interesse e a capacidade da arte europeia de se "valer da arte de culturas não-europeias como inspiração":

Isto pode ter se originado nas primeiras experiências da Renascença Italiana de se valer de uma cultura estranha, temporalmente remota - como a Grécia Helenista - para sua revitalização. Neste aspecto, a verdadeira lição do Renascimento não seria a redescoberta da perspectiva, mas a descoberta da diferença como fonte de inspiração. (PIPER, 2008, p. 168) 
Nesse mundo cambiante e fluido, líquido como prefere Zygmunt Bauman, a busca de um melhor entendimento do lugar da América Latina, de sua arte e de seus artistas no mundo contemporâneo é um enorme desafio; simplificações e precipitações seguramente não têm qualquer valia diante das forças de uma ordem mundial consolidada. Isso, no entanto, não impede que os artistas sonhem com os olhos bem abertos, que deem vazão aos seus delírios, como o do artista venezuelano Javier Téllez ao recorrer a um canhão para a travessia da fronteira entre América Latina e Estados Unidos (One Flew over the Void / Bala perdida, 2005), ou como na nova ordem geopolítica proposta pelo uruguaio Torres García com seu Mapa invertido (1943). 


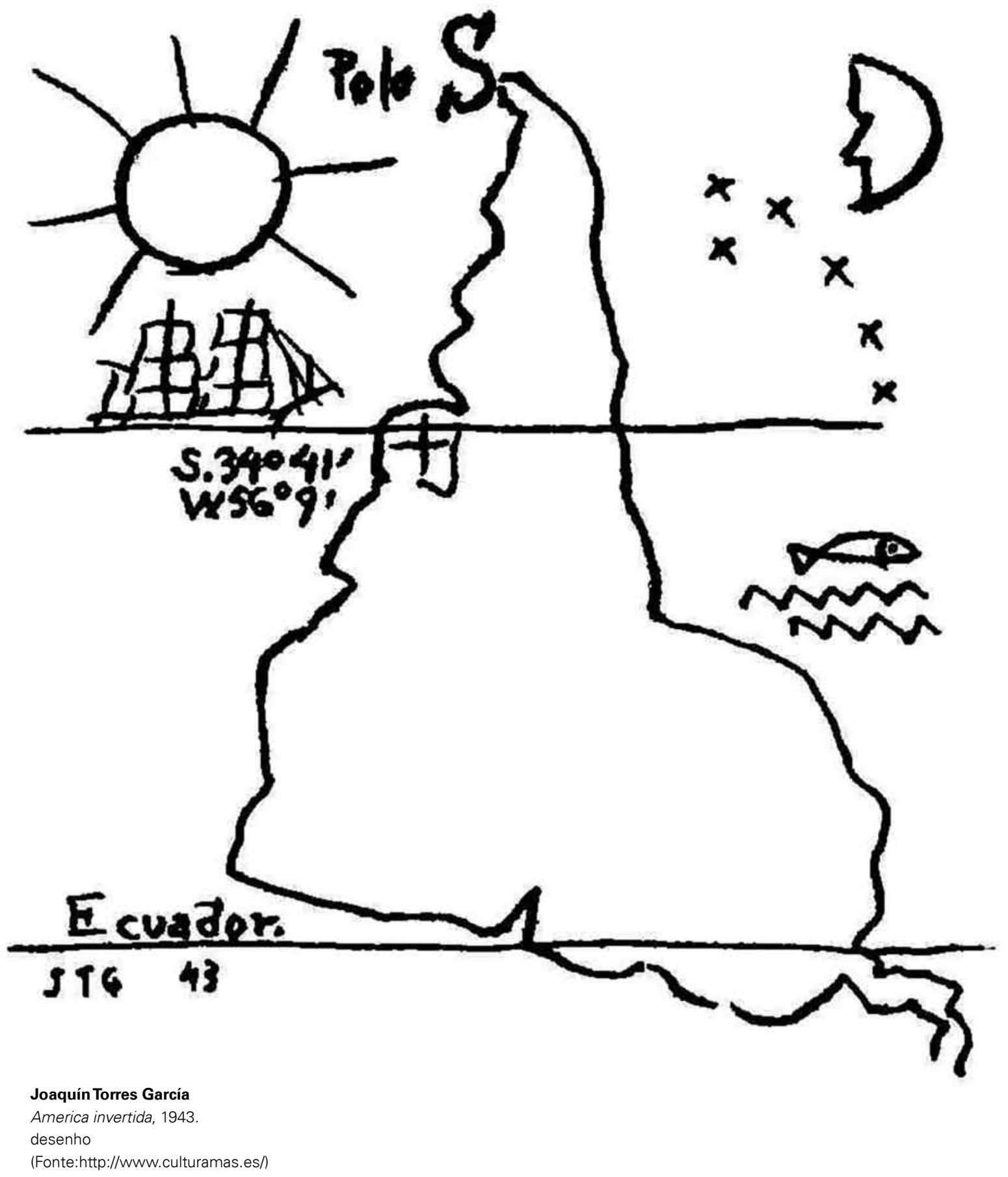




\section{Notas}

1 De acordo com Ana Cavalcanti, "o primeiro artista brasileiro a estudar em Paris, segundo os conhecimentos atuais, foi o pintor Manuel de Araújo Porto-Alegre (1806-1879). Porto-Alegre foi o precursor dos pensionistas do Estado, o primeiro dos alunos da Academia a aperfeiçoar-se na Europa, para onde fora acompanhando seu mestre Jean Baptiste Debret e onde permaneceu de 1831 a 1837". Para a consulta e uma melhor compreensão desse processo ao longo do século XIX ver CAVALCANTI, Ana Maria Tavares. Os Prêmios de Viagem da Academia em Pintura. In: PEREIRA, Sonia Gomes (org.). 185 anos da Escola de Belas Artes. Rio de Janeiro: UFRJ, 2001 / 2002, p. 69-92.

2 Canção composta especialmente para Carmen Miranda por Luís Peixoto e Vicente de Paiva, gravada pela cantora e atriz em 1940.

\section{Referências}

CAVALCANTI, Ana Maria Tavares. Os Prêmios de Viagem da Academia em Pintura. In: PEREIRA, Sonia Gomes (org.). 185 anos da Escola de Belas Artes. Rio de Janeiro: UFRJ, 2001 / 2002, p. 69-92.

GALEANO, Eduardo. As veias abertas da América Latina. Rio de Janeiro: Paz e Terra, 2002.

HALL, Stuart. Que 'negro' é esse na cultura negra? In: Da diáspora: identidades e mediações culturais. Belo Horizonte: Editora UFMG; Brasília: Representação da Unesco no Brasil, 2003.

IANNI, Octavio. A sociedade global. Rio de Janeiro: Civilização Brasileira, 2003.

PIPER, Adrian. A lógica do modernismo. Poiésis, Niterói, n. 11, p. 167-176, nov. 2008.

ZílıIO, Carlos. A querela do Brasil. Rio de Janeiro: Funarte, 1982. 